\title{
Analysis of the Driver's Behavior Characteristics in Low Volume Freeway Interchange
}

\author{
Ronghua Wang, ${ }^{1}$ Jiangbi Hu, ${ }^{2}$ and Xiaoqin Zhang $^{2}$ \\ ${ }^{1}$ College of Architecture and Civil Engineering, Beijing Key Laboratory of Traffic Engineering, Beijing University of Technology, \\ Beijing 100124, China \\ ${ }^{2}$ College of Metropolitan Transportation, Beijing Key Laboratory of Traffic Engineering, Beijing University of Technology, \\ Beijing 100124, China
}

Correspondence should be addressed to Jiangbi Hu; hujiangbi@bjut.edu.cn

Received 28 October 2015; Accepted 24 March 2016

Academic Editor: Yongjun Shen

Copyright (C) 2016 Ronghua Wang et al. This is an open access article distributed under the Creative Commons Attribution License, which permits unrestricted use, distribution, and reproduction in any medium, provided the original work is properly cited.

\begin{abstract}
Drivers' behavior characteristics cannot be ignored in designing freeway interchange facilities in order to improve traffic safety. This paper conducted a field experiment in Qingyin expressway. Four freeway interchanges from K571+538 to K614+932 with relatively low volume were selected, and 12 qualified drivers, 6 car test drivers and 6 truck test drivers, were driving vehicles according to the driving program. GPS and eye-tracking instrument were employed to record running speed, real-time, running track, fixation point, and so forth. Box-plot graphs and Student's $t$-test were used to analyze the 12 data sets of driver's fixation on exit guide signs. Speed-distance curves of effective 11 data sets were plotted to examine the test drivers' behavior in diverging area and merging area. The results indicated that (1) drivers recognize the exit direction signs in $170 \mathrm{~m}-180 \mathrm{~m}$ advanced distance; (2) the diverging influence area is $1000 \mathrm{~m}$ upstream of the diverge point, and the merging influence area is $350 \mathrm{~m}$ downstream of the merge point; (3) NO OVERTAKING sign is recommended to be placed at $350 \mathrm{~m}$ upstream of the diverge point. The results can provide guidance for the design of freeway interchange facilities and management in order to improve traffic safety.
\end{abstract}

\section{Introduction}

Many engineers and researchers found that accident rates are relatively higher in the interchange segments than in other freeway segments. The traffic condition in the vicinity of interchanges is complicated because of diverging, merging, and changing lanes frequently, which easily lead to accidents as a result of driving distress or higher workload. Many researchers have studied about the interchange design and safety, diverging influence area, and merging influence area.

(1) Interchange Design and Safety. Early in 1985, Polus et al. investigated the flow characteristics on acceleration lanes of interchange, and three separate analyses were conducted: the locational distribution of merging places, the acceleration characteristic vehicles, and driver behavior during gap or lag acceptance from the acceleration lanes, which were all helpful for understanding the traffic operation at interchanges [1]. In 1989, Leisch proposed that stopping sight distance is only one of many design and operational considerations in planning an improvement for freeway and interchange reconstruction and pointed out that further study is needed to ascertain the optimum dimensions of all cross-sectional elements to best satisfy safety, operational, and design requirements [2].

In 1998, Smith and Garber reviewed many literatures of diamond interchange (DI) and the single-point urban interchange (SPUI) and evaluated and compared the safety and operational characteristics of the SPUI and DI and to develop guidelines that identify traffic and geometric conditions that favor one over the other [3]. Awad and Janson applied three different modeling approaches to explain truck accidents at interchanges, and the result indicated that the two models, using neural networks and a hybrid system, showed a high level of performance in identifying different patterns of accidents in the training data without presenting training process which showed unsatisfactory results [4].

Sun et al. constructed mathematical model of driver density combining computer simulation and field experiment 
and put forward suggested value of land-saving ramp circular curve radius ensuring traffic safety and service level [5]. Kielian proposed a plan, replacing the loop ramps on the interchange between the Long Island Expressway and Cross Island Parkway in Queens by two new direct connector ramps, to reduce traffic volume and improve operations on local roads [6]. Yang et al. conducted extensive simulation comparison between the optimized signal plans and the results from signal optimization software under various traffic scenarios and proposed an optimization model to maximize the diverging diamond interchange capacity [7].

In the vicinity of highway interchange, Flintsch et al. developed a model to compute the crash rate associated with alternative section spacing, and the research indicated that the minimum spacing from $90 \mathrm{~m}$ to $180 \mathrm{~m}$ results in a $50 \%$ reduction in the crash rate. Flintsch's study can assist policy makers in quantifying the trade-offs of different access management regulations [8].

(2) Interchange Safety Analysis and Evaluation. And also many researchers put efforts on interchange safety analysis and evaluation. Finley and Ullman conducted field studies at freeway interchanges to evaluate the operational impacts of route shield and directional arrow in-lane pavement marking and concluded that the installation of in-lane pavement markings improved operations and safety at the interchanges [9]. Torbic et al. synthesized the current state of knowledge concerning the safety assessment of interchanges, developed a spreadsheet-based computational tool for examining the safety performance of existing interchanges, and identified gaps in knowledge concerning interchange safety assessment [10].

Sadia and Polus presented an interchange complexity model using a database of 25 interchanges based on estimations of aggregated drivers' workload in interchanges, constructed a resulting crash prediction model, and then validated both the use of the model and the resulting crash prediction models, which can be used by highway planners to estimate the complexity of interchange design alternatives for road safety to minimize driver errors and reducing crash occurrences [11]. Haleem et al. applied multivariate adaptive regression splines to develop crash modification factors for median width and inside and outside shoulder widths for different kinds of crash types for urban freeway interchange influence area, and also this further implements crash predictions from the model to identify changes in geometric design features [12].

Fitzpatrick et al. investigated relationships between weaving length, speed, and overall vehicle operations for successive ramps on Texas freeways and proposed updates to current guidance on recommended distances between ramps [13]. Kar and Maji analyzed several conventional and unconventional interchange configurations and all alternatives using Maryland State Highway Administration's (MDSHA) critical lane volume methodology for optimal lane configuration, which described MDSHA's successful testing of a framework in developing the ramp crossover interchange design [14].
(3) Diverging and Merging Area and Other Aspects. Many studies about diverging and merging area have been conducted in order to improve the interchange safety. Ahammed et al. found that merging speed depends on both ramp and speed-change lane based on analysis of traffic behavior of 23 merging sites data and developed a safety performance model to relate the total number of collisions on the acceleration speed-change lane to the features of the merging area including the merging speed, which can be used to evaluate the safety condition on freeway merging areas [15].

Sarvi and Kuwahara undertook a three-year study to investigate traffic behavior and operating characteristic during the merging process under congested traffic conditions and constructed a behavior model which was used to evaluate the capacity of a merging section and develop a variety of intelligent transport system control strategies. The proposed control strategies of Sarvi and Kuwahara's study showed significant improvement over the capacity of merging sections [16]. Shen et al. constructed a relation model between the indicators of the mainline plane and vertical section and the recognition sight distance in the diamond interchange diverging areas, and the analysis results indicated that it is necessary to strengthen the safety precautions so as to guarantee the traffic safety of vehicles driving on the mainline and off the mainline [17].

Other than the researches on merging and diverging area, Sarhan et al. selected 26 interchanges to quantify the effects of ramp terminal spacing and traffic volumes on safety performance through regression analysis, which is in order to address the safety effects of merging and diverging and the interrelationship with geometric features [18].

Fatema et al. focused on analyzing entrance speed-change lanes from a safety point of view in a probabilistic framework and applied regression analysis to quantify the effect of several comprehensive factors on collision occurrence, which provided positive evidence on the validity of probability of noncompliance as a surrogate measure of safety [19]. Le and Porter oversimplified driver behavior and complex interactions between roadway geometrics, traffic operations, and safety, quantified the relationship between ramp spacing and freeway safety, and applied a negative binomial regression model to explore the relationship between ramp spacing and freeway safety, where the result indicated that the expected crash frequency increased as ramp spacing decreased [20].

As the designation of interchange, it aims to accommodate the large traffic volume. Based on this, researches mentioned above mainly figured out the relationship between interchange design and safety. However, another condition exists that the traffic volume of some interchanges is relatively low in some region of China. As a result, drivers are inclined to driving too fast and changing lanes much more frequently even when driving through the diverging segments, merging segments, and weaving segments, which would lead to traffic accidents. As considering little research on this theme, this paper explored drivers' behavior characteristics through field experiments, which try to provide materials and evidence for interchange design and operation with low volume. 
TABLE 1: Interchange profile.

\begin{tabular}{lcccc}
\hline ID & Interchange forms & \multicolumn{2}{c}{ Design speed $(\mathrm{km} / \mathrm{h})$} & Interchange spacing $(\mathrm{km})$ \\
& & Mainline & Ramp & $40 / 60$ \\
NJ & Single trumpet & 120 & $40 / 60$ & 14.4 \\
ZX & Single trumpet & 120 & 40 & 13.5 \\
LC & Single trumpet & 120 & 40 & 15.5 \\
DY & Double trumpet & 120 & & \\
\hline
\end{tabular}

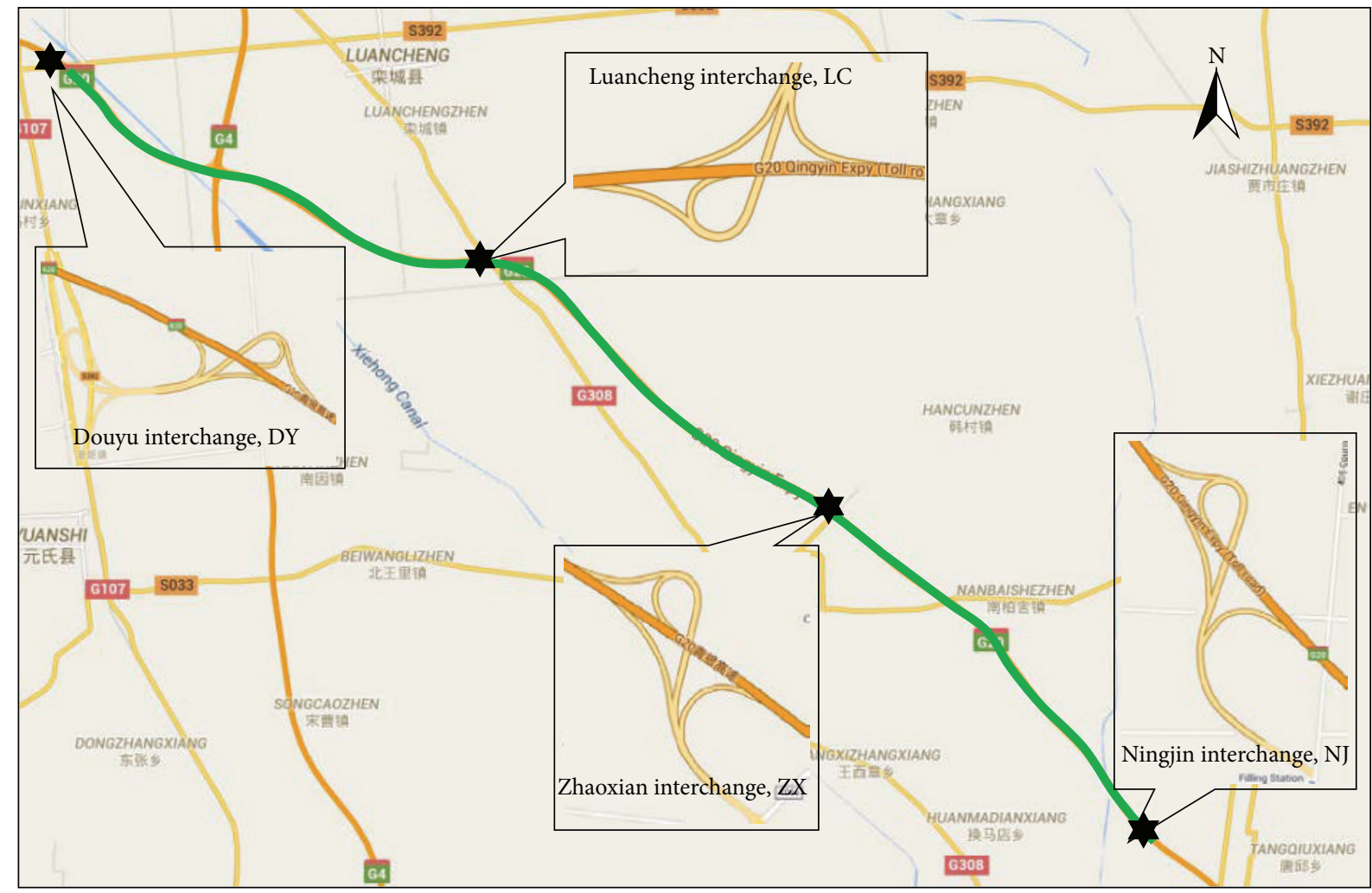

Test road segment

FIGURE 1: Test road segment and the specific locations of four test interchanges.

\section{Materials and Methods}

2.1. Test Location Selection. Considering the test condition and research needs, we choose Qingyin expressway from $\mathrm{K} 571+538$ to $\mathrm{K} 614+932$ as the test road segment and the total length is $43.4 \mathrm{~km}$ (Figure 1). The test road segment was designed as fully enclosed overpass, bidirectional four lanes, and bituminous concrete pavement and the design speed was $120 \mathrm{~km} / \mathrm{h}$. Four interchanges with relatively low volume were chosen as specific test locations to study drivers' characteristics. NJ, ZX, LC, and DY are abbreviations of Ningjin interchange, Zhaoxian interchange, Luancheng interchange, and Douyu interchange, respectively. Meanwhile, the traffic capacity of the four interchanges above is relatively small (ADT $\leq 1000$ ), which ensure the speed of test vehicles is of stable flow with no constraints by other drivers or vehicles (Table 1). These four interchanges selected are close to each other $(14.4 \mathrm{~m}, 13.5 \mathrm{~m}$, and $15.5 \mathrm{~m})$. The value of the entrance ramp radius is basically the same in the direction of NJ-DY. Under the low traffic volume condition, test drivers finish a complete test progress according to the driving program. This method can reduce the difference of test data between different interchanges in order to obtain the drivers' behavior characteristics as much as possible.

\subsection{Test Vehicles and Drivers}

2.2.1. Test Vehicle Selection. Even though the design speed of the tested road segment is $120 \mathrm{~km} / \mathrm{h}$, the speed limits of different lanes for vehicles are different in the actual operation phase. The speed limit of the lane nearest to the center of the expressway is $120 \mathrm{~km} / \mathrm{h}$ for cars, whereas trucks cannot be permitted to run in this lane. The speed limit of the rightmost lane is $80 \mathrm{~km} / \mathrm{h}$ for cars as well as $60 \mathrm{~km} / \mathrm{h}$ for trucks. The remarkable difference between cars and trucks is 


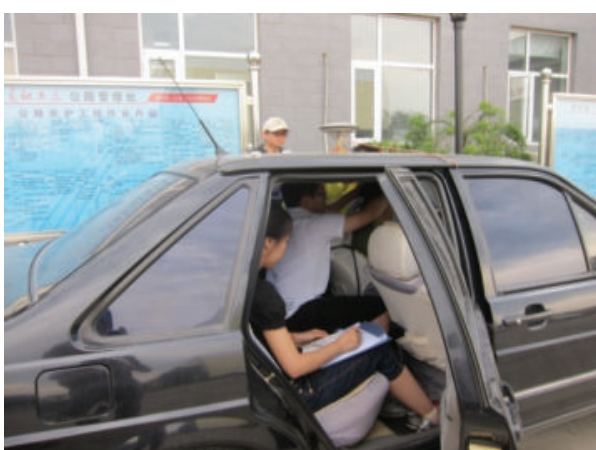

(a)

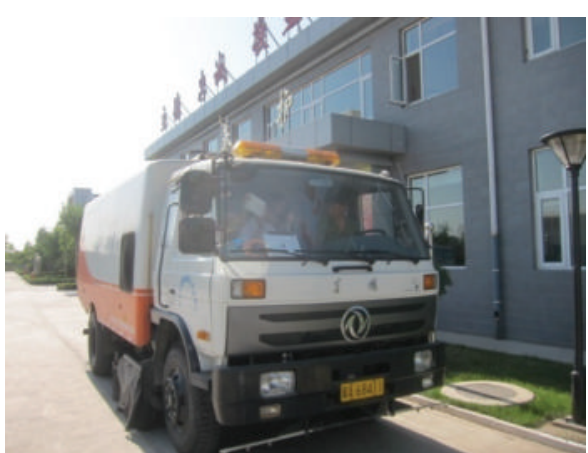

(b)

FIGURE 2: Typical test vehicles, car (a) and truck (b).

the dimensions of these two kinds of vehicles, which result in different driver eye heights and object heights. Before the uncertainty is the fact that vehicle types have an impact on driver characteristics in low volume interchange area; test vehicles were classified into car and truck. In accordance with the most common type of cars and truck running in the tested road segment, the tested car and truck were chosen as shown in Figure 2.

2.2.2. Test Driver Selection. Test drivers were selected randomly, and they are healthy with normal response, normal vision, no waist pain, no history of cardiovascular, and so forth. Meanwhile, they must meet the following requirements: more than 10 years of driving experience; average level of driving proficiency; 8 hours of sufficient sleep; the latest 72 hours without alcohol, and 3 hours without tea and coffee. All requirements mentioned above ensure the validity of test results. As a result, 12 qualified drivers were selected, 6 car drivers and 6 large truck drivers. They are all male and their age is ranging from 30 to 49 years.

\subsection{Equipment and Driving Program}

2.3.1. Equipment. A dynamic GPS (NovAtel DL-V3) was employed for recording testing time, driving speeds, running track, distance, and so forth (Figures 3(a) and 3(b)). The eye-tracking instrument (SMI iViewX HED) was employed for recording fixation points of drivers as test time goes on (Figures 3(c) and 3(d)). Dynamic GPS and eye-tracking system were used simultaneously to correlate the fixation points with running track and distance.

2.3.2. Driving Program. After setting up all equipment, every driver was asked to drive hundreds of meters in order to adapt to drive with devices. The test procedure of one segment is as follows: (a) the test vehicles were driven into the tested road segment from NJ interchange entrance ramp; (b) when passing the 4 th notice sign of the next interchange ( $\mathrm{ZX})$, the tested vehicle entered the transition section-deceleration lane and then exited the interchange; (c) after driving through the toll booth, the driver was turning the tested vehicle around back to the tested road segment. The schematic diagram of testing route collected by dynamic GPS is shown in Figure 4, and the complete driving route is NJ-ZX-LC-DY-DY-LC-ZXNJ.

\section{Data Analysis and Results}

3.1. Advanced Recognition Distance of Exit Direction Signs. According to the driving program, there were 12 different data sets, which were composed of 6 car test data sets (C1\#, C2\#, C3\#, C4\#, C5\#, and C6\#) and 6 truck test data sets (T1\#, T2\#, T3\#, T4\#, T5\#, and T6\#). During a complete test progress, every test driver recognized exit direction signs 3 times in each direction, from NJ to DY and from DY to NJ. From the records of eye-tracking instrument, when the fixation point of test drivers is in the area of the exit direction guide for the first time as shown in Figure 5(a), it is considered that the exit direction guide is recognized. Simultaneously, the traveling distance is written down. The time and the corresponding distance are written down when the test cars or trucks are parallel with the exit direction signs.

In the field test, every test driver can be considered an independent sample when recognizing the exit direction sign. 72 independent samples were obtained that 12 test drivers recognized exit direction signs for 6 times. The boxplot graphs show different trends for the metrics calculated for each exit (Figure 6). The median advanced recognition distance of each exit is $170 \mathrm{~m}, 170 \mathrm{~m}, 167.5 \mathrm{~m}, 170 \mathrm{~m}, 187.5 \mathrm{~m}$, and $200 \mathrm{~m}$, and there is not any outlier. Taking the car test drivers samples as a whole and truck test drivers' samples as a whole, two groups of data sets are examined if there is any significant difference.

Student's $t$-test was employed to test that there is no significant difference between the means of car test drivers data set and truck test drivers data set. After calculation, $t=1.92$ is less than the critical value for $p=2.25$, so the null hypothesis cannot be rejected that the means of the advanced recognize distance of car test drivers is consistent with truck test drivers. And without any outlier, the statistical mean is more stable than the median. The mean of advanced recognition distances of the exit direction sign is $178 \mathrm{~m}$. 


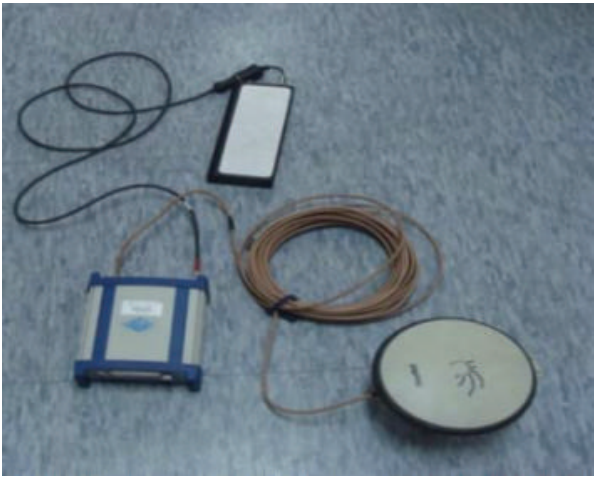

(a)

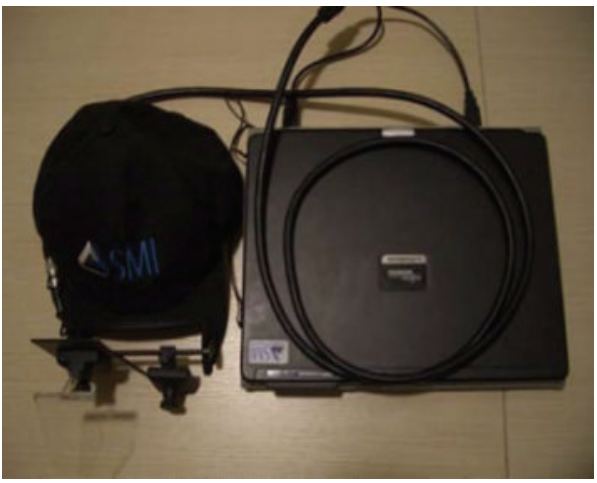

(c)

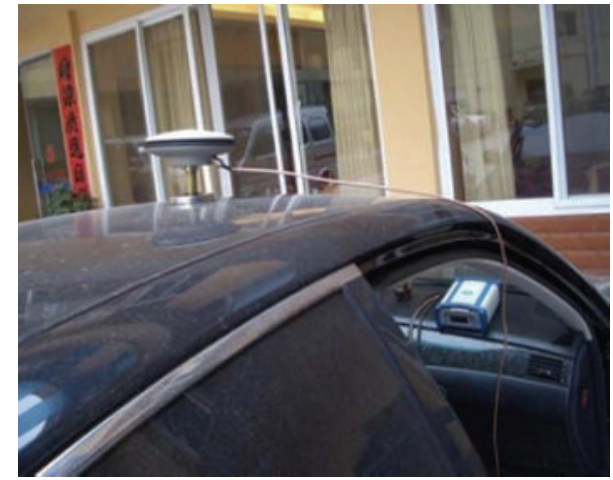

(b)

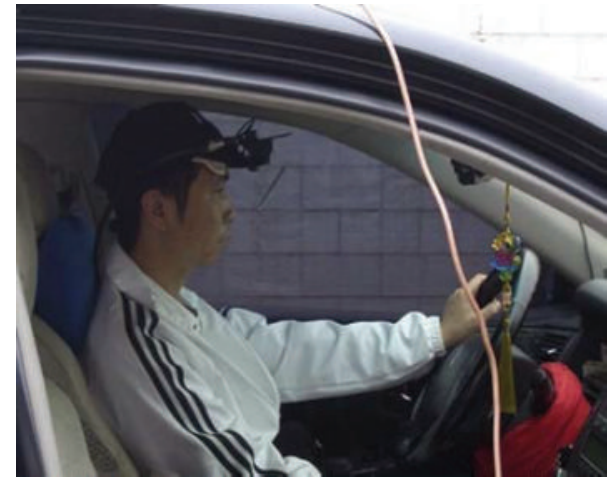

(d)

FIGURE 3: Test equipment, GPS ((a), (b)) and eye-tracking instrument ((c), (d)).

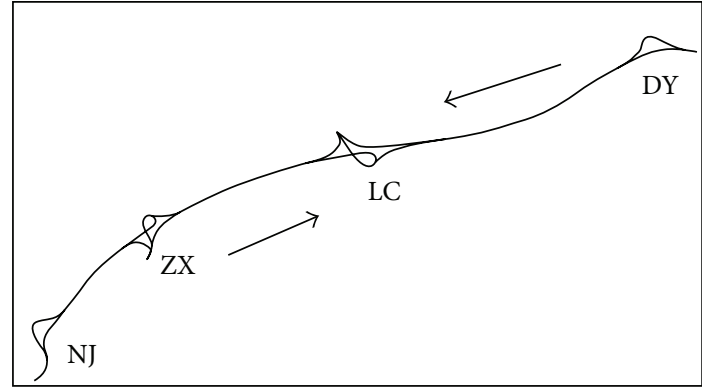

FIGURE 4: Driving route schematic diagram.

Considering the highway engineering characteristics and practice, the advanced recognizing distance of exit direction signs is $170 \mathrm{~m}-180 \mathrm{~m}$.

What is more is that the test driver will recognize the exit direction sign even earlier when the test vehicle is at a higher speed. Due to the high running speed, the driver needs deep focus to improve the efficiency for getting traffic information.

3.2. Interchange Influence Area. Interchange influence area of expressway includes not only the diverging area, merging area, and weaving area, but also the mainline area in which traffic direction signs or some other traffic facilities are placed. When driving in these areas, driving workload is relatively higher than other segments. Drivers need to keep a safe spacing between other vehicles and recognize the merging section and diverging section ahead of vehicles and recognize the traffic direction signs to adjust running speed or change lanes to keep a safe operating condition. On the basis of complex maneuver and traffic organization, the determination of the interchange influence area can help improve traffic safety.

According to HCM2010 published by the Institute of Transportation Engineers, the merging influence area is $1500 \mathrm{ft}$ downstream of the merge point, and the diverging influence area is $1500 \mathrm{ft}$ upstream of the diverge point, and the weaving influence area is the entire length of the weaving segment plus $500 \mathrm{ft}$ upstream of the input boundary and $500 \mathrm{ft}$ downstream of the output boundary [21]. The methodology in the HCM2010 is based on the traffic capacity, level of service, and density range. However, as early as recognizing the direction signs by drivers, driving performance has already impacted the traffic condition of diverging area. And also, merging influence area should be the end of the point at which merging movements finish. Through actual driving field test, we examined the driving behavior characteristics of approaching to interchange and departing from the interchange and attempt to determine the interchange influence area based on driving behavior characteristics.

3.2.1. Diverging Influence Area. Because of analytical needs, interchanges with relatively low volume were chosen so that 


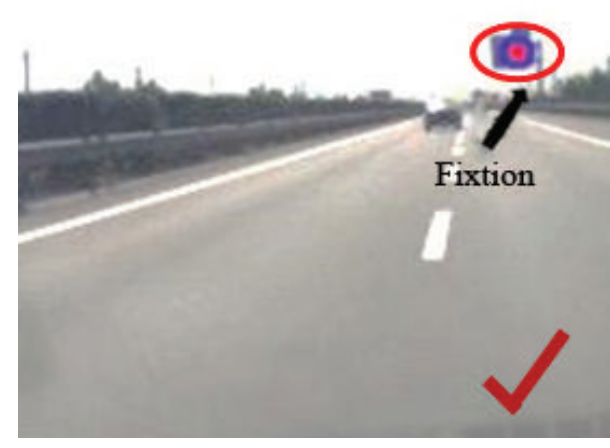

(a)

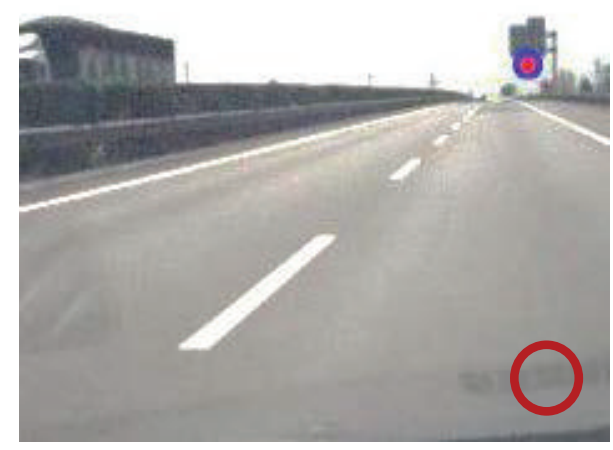

(b)

FIgURE 5: Fixations of the drivers to recognize and read notice signs at the interchange exits.

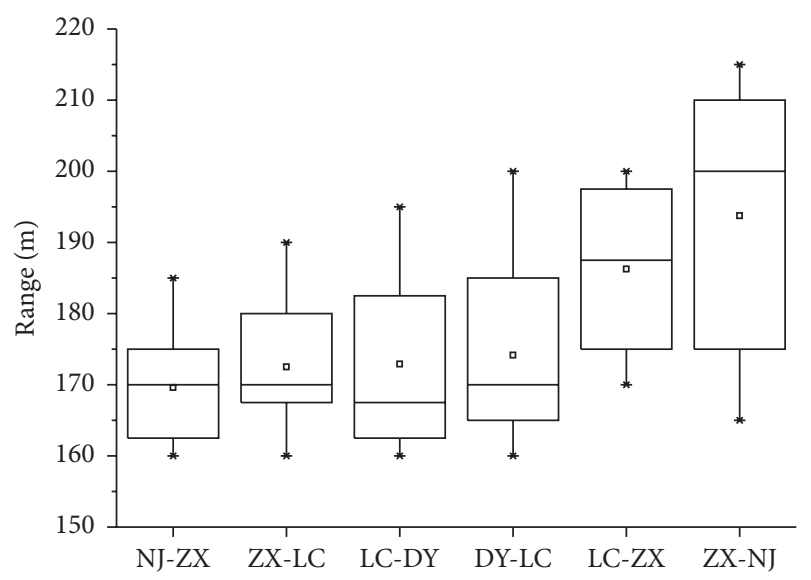

FIGURE 6: Box-plot of advanced recognition distance of exit direction sign of each interchange exit.

the test vehicles are of little constraints by other drivers or vehicles, which keep a stable flow situation. However, in the actual testing, one car test driver overtook a truck and drove into ramp as approaching the deceleration lane to run off the mainline. This test car did not perform a stable flow situation, and the corresponding data cannot reflect the driver's behavior characteristics. As a result, another five data sets of car test drivers and six data sets of truck test drivers were analyzed to examine the drivers' behavior characteristics.

From the data of GPS, speed-distance curves of the rest of 11 test vehicles were plotted when they drive out of the mainline of the test road segment. Taking the NJ-ZX section as an example, speed-distance curves of five test cars were displayed as in Figure 7.

When test cars were parallel to $2 \mathrm{~km}$ advance guide sign of the next exit, instantaneous velocity was written down. From Figure 7, in the segment between $2 \mathrm{~km}$ advance guide sign and $1 \mathrm{~km}$ advance guide sign, every test car maintained a stable running speed between $100 \mathrm{~km} / \mathrm{h}$ and $120 \mathrm{~km} / \mathrm{h}$, which is consistent with the design speed of the test expressway. Even if the test drivers recognized the advance guide sign of the next exit, they did not slow down the test cars. In the segment between $1 \mathrm{~km}$ advance guide sign and $500 \mathrm{~m}$

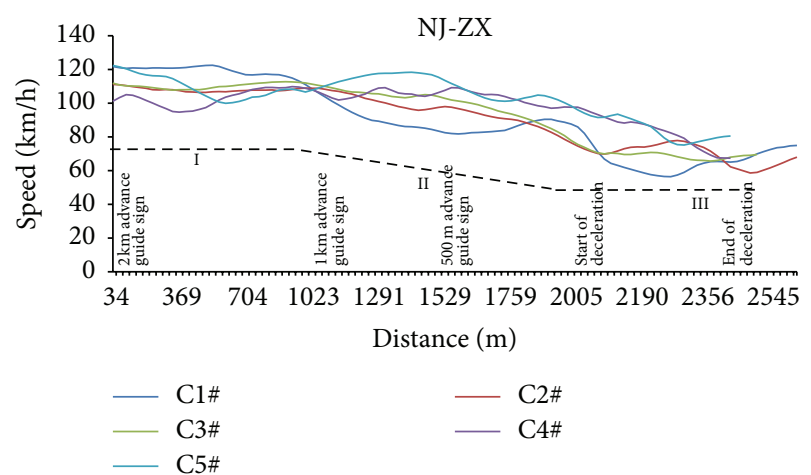

FIGURE 7: Speed-distance curves of five test cars driving out of the mainline, NJ-ZX.

advance guide sign, test cars showed an obvious tendency of deceleration after test drivers recognized the $1 \mathrm{~km}$ advance guide sign, and the running speed reduced $10 \mathrm{~km} / \mathrm{h}-20 \mathrm{~km} / \mathrm{h}$. Passing the $500 \mathrm{~m}$ advance sign, all test cars began to decelerate to $60 \mathrm{~km} / \mathrm{h}-90 \mathrm{~km} / \mathrm{h}$ and drove into the deceleration lane through the transition segment.

It is conducted that there are three obvious phases from $2 \mathrm{~km} / \mathrm{h}$ advance guide sign to the end of deceleration point. As seen in Figure 7, the test speed kept a stable level in phase I, and then the test car decelerated obviously in phase II, and last the test car decelerated into a relatively low speed in order to drive out of the interchange area safely in phase III.

The speed-distance curves of test cars displayed the same tendency in other five segments of ZX-LC, LC-DY, DYLC, LC-ZX, and ZX-NJ. More than that, the speed-distance curves of test trucks displayed the same tendency except the corresponding speed of three phases was different. The speed kept $60 \mathrm{~km} / \mathrm{h}-80 \mathrm{~km} / \mathrm{h}$ in phase I, and test truck began to decelerate $10 \mathrm{~km} / \mathrm{h}-20 \mathrm{~km} / \mathrm{h}$ in phase II, and last the test truck decelerated into $30 \mathrm{~km} / \mathrm{h}-40 \mathrm{~km} / \mathrm{h}$ in phase III.

Based on analysis of variance laws of running speed, $2 \mathrm{~km} / \mathrm{h}$ advance guide sign has little impact on drivers' behavior. Drivers manipulate vehicles to decelerate mainly after recognizing the $1 \mathrm{~km}$ advance guide signs, which conduct that $1 \mathrm{~km}$ advance guide sign has significant impact on drivers' behavior. From this moment, decelerating behavior has already influenced the traffic flow in the mainline. As a result, 


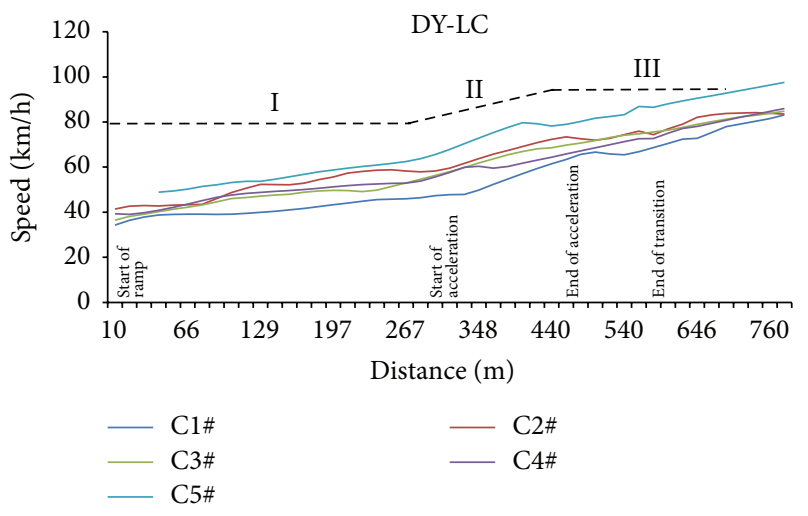

FIGURE 8: Speed-distance curves of five test cars driving into the mainline, DY-LC.

the diverging influence area is $1000 \mathrm{~m}$ upstream of the diverge point according to actual drivers' behavior characteristic.

3.2.2. Merging Influence Area. Taking the same method and from the data of GPS, speed-distance curves of the rest of 11 test vehicles were plotted when they drive into the mainline of the test road segment. Taking the DY-LC section as an example, speed-distance curves of five test cars were displayed as in Figure 8.

Test cars run into the ramp entrance at the speed of $40 \mathrm{~km} / \mathrm{h}$ and then speed up with a relatively lower acceleration. When test cars drove into the acceleration lane at the speed of $40 \mathrm{~km} / \mathrm{h}-60 \mathrm{~km} / \mathrm{h}$, the running speed showed a remarkable boost to $60 \mathrm{~km} / \mathrm{h}-80 \mathrm{~km} / \mathrm{h}$. At the end of acceleration, the test cars kept a relative stable level of speed a while and then speed up into the mainline.

In the field test of vehicle driving into mainline through the ramp, these were also three phases with obvious different acceleration levels as shown in Figure 8. The test cars kept a stable and lower acceleration level in phase I, and then a higher acceleration level occurred in phase II. In phase III, vehicles ran with either a lower acceleration in outside lane or a higher acceleration into overtaking lane.

The speed-distance curves of test trucks displayed the same tendency except the corresponding speed of three phases was different. The running speed kept $40 \mathrm{~km} / \mathrm{h}$ in phase I and accelerated into $60 \mathrm{~km} / \mathrm{h}$ in phase II. In phase III, test trucks were running in the outside lane at the speed of $60 \mathrm{~km} / \mathrm{h}-80 \mathrm{~km} / \mathrm{h}$.

Variance laws of running speed were analyzed when vehicles are driven out of the interchange. It is obvious that the traffic flow is influenced by the vehicles driving out of interchange to the mainline in phase III. From the data of GPS, vehicles will travel a $250 \mathrm{~m}-350 \mathrm{~m}$ (10 s-15 s) distance at the speed of $60 \mathrm{~km} / \mathrm{h}-80 \mathrm{~km} / \mathrm{h}$, and then the traffic flow in the mainline can keep a stable situation. From the safety aspect, the merging influence area is $350 \mathrm{~m}$ downstream of the merge point.

3.3. Vehicle Traveling Route Characteristic. Based on the traffic capacity of expressway, there are more than two lanes in each driving direction. Generally, most of cars are driven in inside lane or overtaking lane, whereas most of trucks are driven in the outside lanes. As approaching the interchange exits, car drivers need to change from the inside lane to the outside lane guided by the advance guide signs and exit direction sign. And then cars are driven off the mainline through transition segment and deceleration lane. The traveling route was shown in Figure 9(a).

However, when a car is driven in outside lane and is going to run off the mainline through interchange, there is a truck running at a low speed in front of the car. The car driver is inclined to speed up and overtake the truck to drive off the mainline. The route is shown in Figure 9(b).

In the actual field test, a test car is driving as this route in the segments ZX-LC and ZX-NJ and this overtaking behavior is dangerous (Figure 10). The speed of the truck ahead is $60 \mathrm{~km} / \mathrm{h}$ or even lower, which will facilitate overtaking. From the GPS data, the car was running at the speed of $80 \mathrm{~km} / \mathrm{h}$ originally and then accelerated to $100 \mathrm{~km} / \mathrm{h}$ in $3 \mathrm{~s}-3.5 \mathrm{~s}$. The car driver spent $9 \mathrm{~s}$ at most to overtake and the car was driven into transition segment to run off the mainline. This unsafe overtaking distance is $326.7 \mathrm{~m}-337.8 \mathrm{~m}$. Even if the car is overtaking at $110 \mathrm{~km} / \mathrm{h}$ or even higher, it cannot be driven into the deceleration lane safely. As discussed above, this study proposes that a NO OVERTAKING sign should be placed at $350 \mathrm{~m}$ upstream of the diverge point.

\section{Discussion}

In recent several decades, the level of design and construction of the expressway has been developed significantly. Without any doubt, researchers and engineers spare no efforts to improve the traffic safety on the expressway from various aspects, such as geometric design $[22,23]$, transport facilities [24], traffic flow [25], and driver behavior [26]. Many studies indicated that traffic accidents usually reflect human factors [27], where understanding drivers' behavior under many kinds of traffic condition is very important. Examining drivers' behavior characteristics is substantial for providing a safe transportation environment in which drivers can manage interaction with both the roadway and other drivers [25].

In the low volume interchange area, the drivers' behavior characteristics have been studied in order to provide basis for further optimizing the traffic facilities. The advanced recognition distance of exit guide sign can provide references for set position, color, and panel design of exit guide sign according to drivers' recognition characteristics. For the diverging influence area and merging influence area, the corresponding results can improve the traffic safety through safety facilities within valid range. In the vicinity of interchange, NO OVERTAKING sign can restrict dangerous driving performance to avoid accidents as much as possible.

\section{Conclusion}

This paper has examined the drivers' behavior characteristics when driving across expressway interchanges through field test and found several phenomena: (1) drivers will recognize the exit direction guide in a certain advanced distance; (2) 


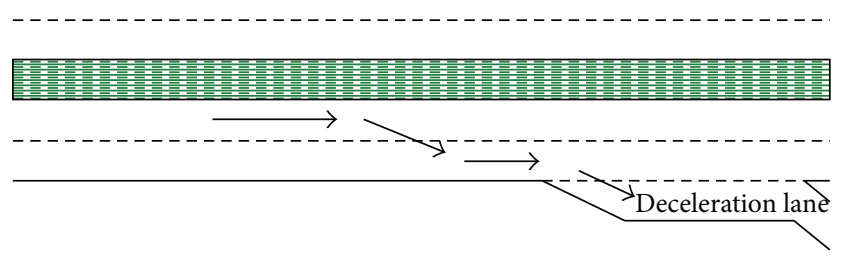

(a)

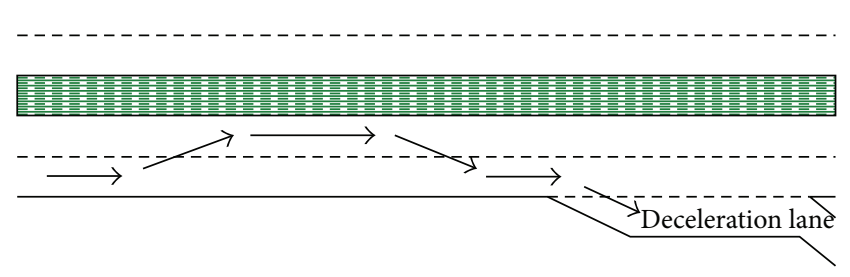

(b)

FIGURE 9: Route of car traveling out of the mainline.

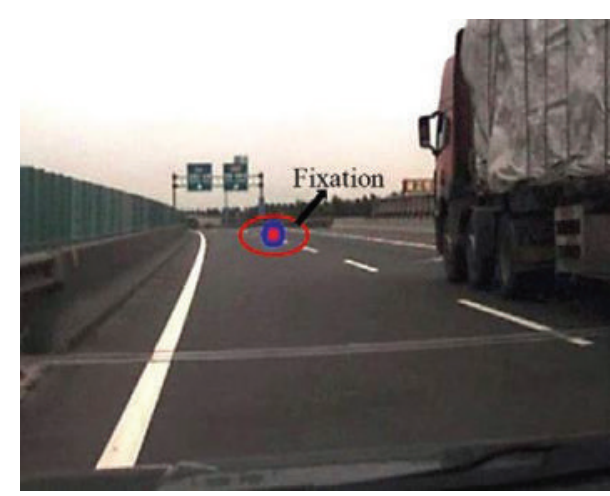

(a)

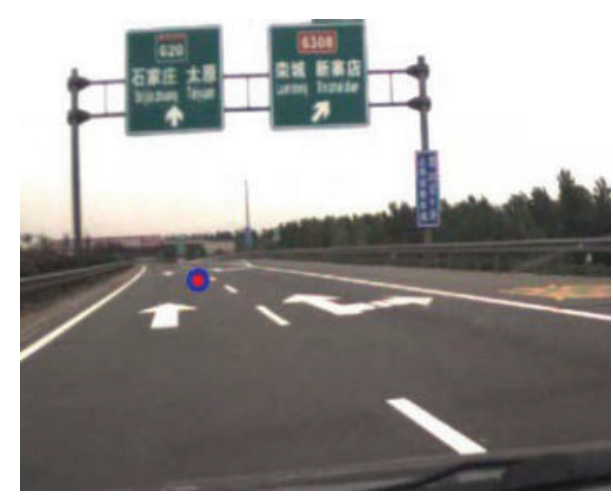

(b)

FIGURE 10: Overtaking behavior when a test car is driven off the mainline, ZX-LC.

$2 \mathrm{~km}$ advanced guide sign has no impact on driving behavior; (3) driver needs $10 s-15 s$ to achieve a stable traveling condition after merge point; (4) it is dangerous for overtaking when the driver is approaching to interchange exit.

Four interchanges with relative low volume along Qingyin expressway from K571+538 to K614+932 were selected. 6 car test drivers and 6 truck test drivers followed the driving program and finished a complete test route NJ-ZXLC-DY-DY-LC-ZX-NJ. GPS and eye-tracking instrument were employed to record fixation points, testing time, driving speeds, running track, distance, and so forth. From the characteristics analysis of drivers' eye movement, test drivers are inclined to recognize the exit direction sign in advanced distance. Through GPS records and Student's $t$-test, it is conducted that the advanced recognize distance of exit direction signs is $170 \mathrm{~m}-180 \mathrm{~m}$.

Through analysis of the test drivers' behavior when approaching the interchange exit, $2 \mathrm{~km}$ advanced guide sign has no impact on drivers' behavior. They begin to decelerate after recognizing the $1 \mathrm{~km}$ advanced guide sign. When driving into the mainline from the entrance ramp, vehicles will keep a stable running situation after a certain distance from the merging point. According to the GPS records, the diverging influence area is $1000 \mathrm{~m}$ upstream of the diverge point, and the merging influence area is $350 \mathrm{~m}$ downstream of the merge point.

From a special car test driver's record, it is found that it is dangerous for overtaking when approaching interchange exit. After analysis and calculation, it is recommended to place a NO OVERTAKING sign at $350 \mathrm{~m}$ upstream of the diverge point.

\section{Competing Interests}

The authors declare that there are no competing interests regarding the publication of this paper.

\section{Acknowledgments}

This work was supported by National Natural Science Foundation of China (Project no. 61271371) and partially supported by National Natural Science Foundation of China (Project no. 61531005).

\section{References}

[1] A. Polus, M. Livneh, and J. Factor, "Vehicle flow characteristics on acceleration lanes," Journal of Transportation Engineering, vol. 111, no. 6, pp. 595-606, 1985.

[2] J. P. Leisch, "Horizontal sight distance considerations in freeway and interchange reconstruction," Transportation Research Record, no. 1208, pp. 80-84, 1989.

[3] M. J. Smith and N. J. Garber, "Guidelines for selecting singlepoint urban and diamond interchanges. Nationwide survey and literature review," Transportation Research Record, no. 1612, pp. 48-54, 1998.

[4] W. H. Awad and B. N. Janson, "Prediction models for truck accidents at freeway ramps in Washington state using regression 
and artificial intelligence techniques," Transportation Research Record, vol. 1635, no. 1, pp. 30-36, 1998.

[5] J. Sun, N. Yang, J. Li, J. Qiao, and J. Qiao, "Research on interchange ramp circular curve radius based on land-saving method," in Proceedings of the International Conference on Green Building, Materials and Civil Engineering, pp. 4109-4114, Transportation Technology Publications, Shangri-La, China, 2011.

[6] J. Kielian, "Context-sensitive design resolves interchange problems," Better Roads, vol. 75, no. 3, pp. 60-64, 2005.

[7] X. Yang, G.-L. Chang, and S. Rahwanji, "Development of a signal optimization model for diverging diamond interchange," Journal of Transportation Engineering, vol. 140, no. 5, Article ID 04014010, 2014.

[8] A. M. Flintsch, H. Rakha, M. Arafeh et al., "Safety impacts of access control standards on crossroads in the vicinity of highway interchanges," Transportation Research Record, vol. 2075, pp. 42-52, 2008.

[9] M. D. Finley and B. R. Ullman, "Field evaluation of inlane pavement markings in advance of freeway interchanges," Transportation Research Record, no. 2250, pp. 32-40, 2011.

[10] D. J. Torbic, D. W. Harwood, D. K. Gilmore, K. R. Richard, and J. G. Bared, "Safety analysis of interchanges," Transportation Research Record, no. 2092, pp. 39-47, 2009.

[11] R. Sadia and A. Polus, "Interchange complexity model and related safety implications," Journal of Transportation Engineering, vol. 139, no. 5, pp. 458-466, 2013.

[12] K. Haleem, A. Gan, and J. Lu, "Using multivariate adaptive regression splines (MARS) to develop crash modification factors for urban freeway interchange influence areas," Accident Analysis and Prevention, vol. 55, pp. 12-21, 2013.

[13] K. Fitzpatrick, R. J. Porter, G. Pesti, C.-L. Chu, E. S. Park, and T. Le, "Guidelines for spacing between freeway ramps," Transportation Research Record, vol. 2262, pp. 3-12, 2011.

[14] P. P. Kar and A. Maji, "Ramp crossover interchange: developing the hybrid unconventional interchange," Institute of Transportation Engineers, vol. 83, no. 5, pp. 28-35, 2013.

[15] M. A. Ahammed, Y. Hassan, and T. A. Sayed, "Modeling driver behavior and safety on freeway merging areas," Journal of Transportation Engineering, vol. 134, no. 9, pp. 370-377, 2008.

[16] M. Sarvi and M. Kuwahara, "Using ITS to improve the capacity of freeway merging sections by transferring freight vehicles," IEEE Transactions on Intelligent Transportation Systems, vol. 9, no. 4, pp. 580-588, 2008.

[17] Q. Shen, S. Yang, Y. Zhao, and H. Cao, "Analysis on mainline alignment index in diamond interchange diverging areas," Journal of Harbin Institute of Technology, vol. 47, no. 9, pp. 9094, 2015.

[18] M. Sarhan, Y. Hassan, and A. O. Abd El Halim, "Safety performance of freeway sections and relation to length of speedchange lanes," Canadian Journal of Civil Engineering, vol. 35, no. 5, pp. 531-541, 2008.

[19] T. Fatema, K. Ismail, and Y. Hassan, "Validation of probabilistic model for design of freeway entrance speed change lanes," Transportation Research Record, vol. 2460, no. 1, pp. 97-106, 2014.

[20] T. Le and R. Porter, "Safety evaluation of geometric design criteria for spacing of entrance-exit ramp sequence and use of auxiliary lanes," Transportation Research Record, vol. 2309, pp. 12-20, 2012.
[21] U. S. National National Research Council and Transportation Research Board, HCM 2010: Highway Capacity Manual, Transportation Research Board, Washington, DC, USA, 2010.

[22] J. L. Hochstein, T. H. Maze, R. R. Souleyrette et al., "Rural expressway intersection design guidance: suggestions for AASHTO green book and manual on uniform traffic control devices," Transportation Research Record, no. 2195, pp. 47-57, 2010.

[23] W. W. Myint, "Study on geometric design of nay pyi tawmandalay expressway and possible improvements; sagarinnmyinsain portion," World Academy of Science, Engineering and Technology, vol. 75, pp. 621-625, 2011.

[24] S. Blair, "Tucson freeway interchange juggles traffic, utilities and archaeology," Engineering News-Record, vol. 268, no. 13, 2012.

[25] K. Heaslip, C. Louisell, and J. Collura, "Evaluating the impact of driver behavior on traffic flow and safety in freeway work zones," in Proceedings of the 14th World Congress on Intelligent Transport Systems (ITS '07), pp. 458-465, October 2007.

[26] Z. Guo, H. Wan, Y. Zhao, H. Wang, and Z. Li, "Driving simulation study on speed-change lanes of the multi-lane freeway interchange," Procedia-Social and Behavioral Sciences, vol. 96, pp. 60-69, 2013.

[27] L. Malta, C. Miyajima, and K. Takeda, "A study of driver behavior under potential threats in vehicle traffic," IEEE Transactions on Intelligent Transportation Systems, vol. 10, no. 2, pp. 201-210, 2009. 


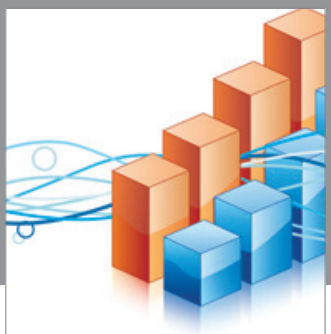

Advances in

Operations Research

vatem alat4

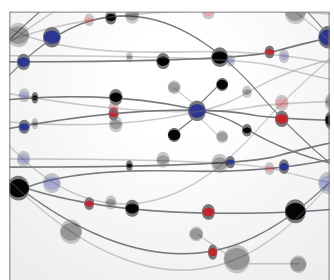

\section{The Scientific} World Journal
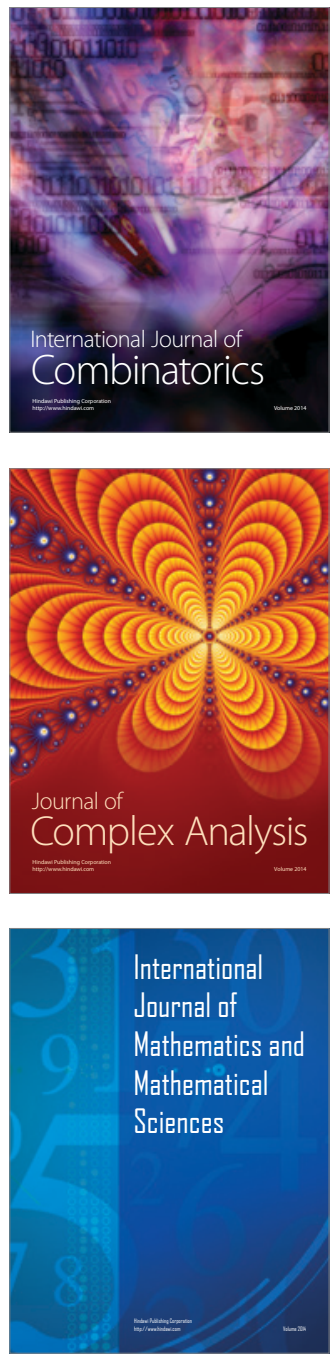
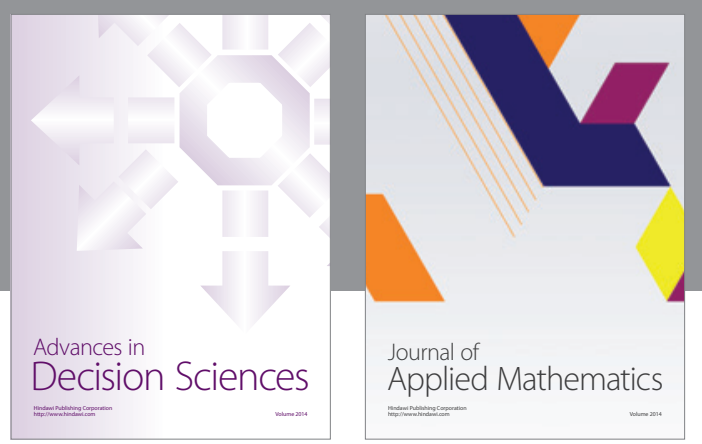

Algebra

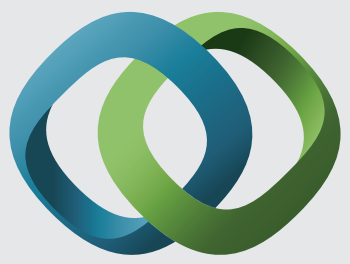

\section{Hindawi}

Submit your manuscripts at

http://www.hindawi.com
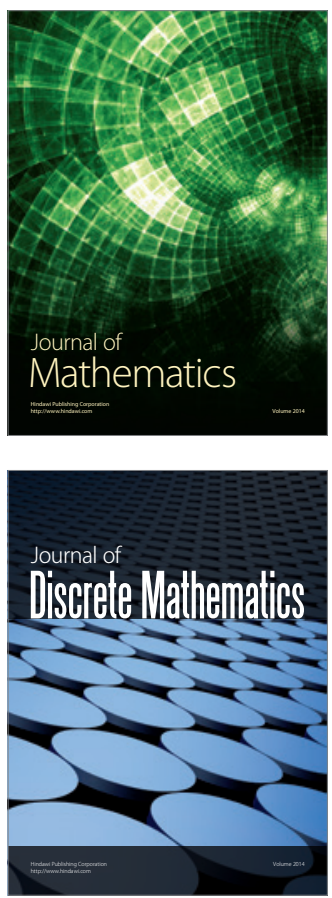

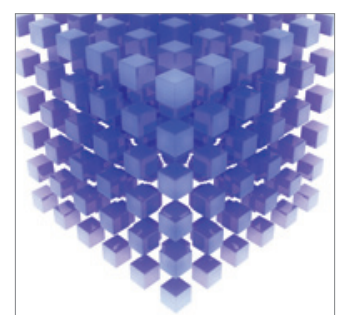

Mathematical Problems in Engineering
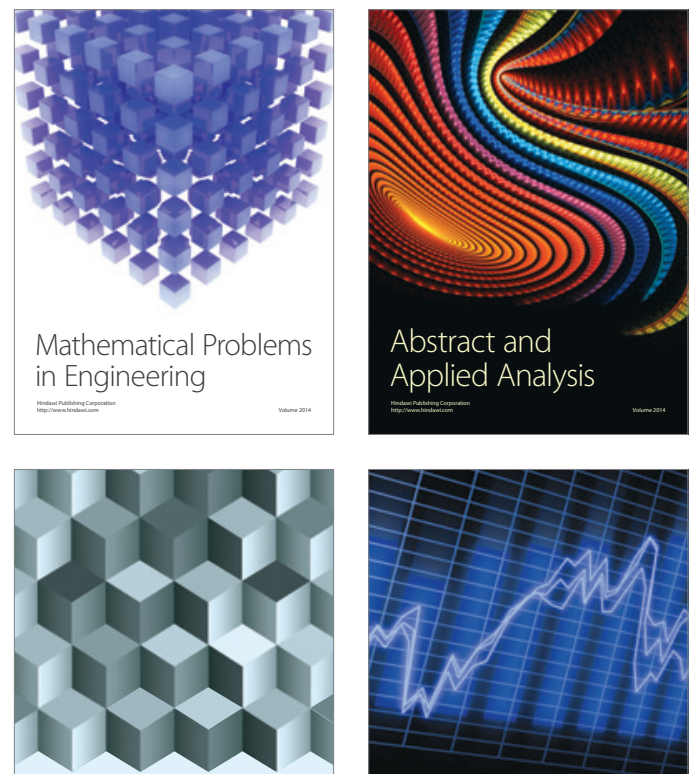

Journal of

Function Spaces

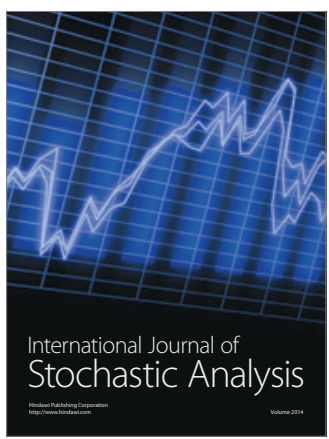

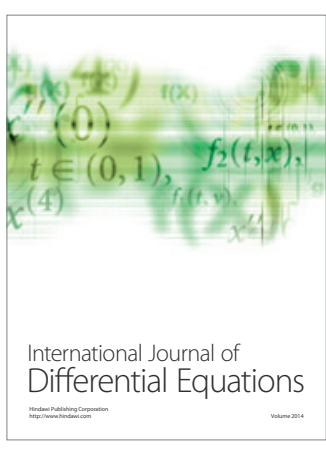
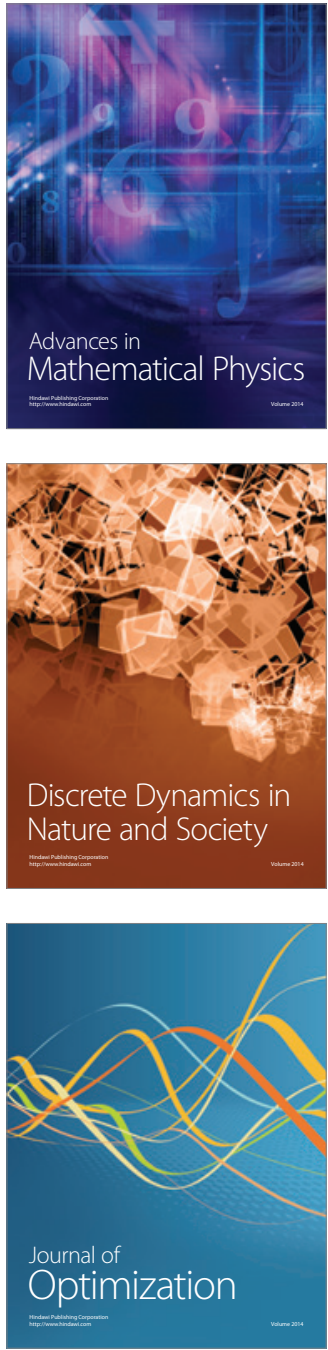